\title{
Proceeding
}

Supplementary Issue: Winter Conferences of Sports Science. Costa Blanca Sports Science Events, 22-23 March 2021. Alicante, Spain.

\section{Development of digital literacy and competence of future sports teachers in the physical and educational environment}

\author{
ELMIRA SH. SALIMZYANOVA ${ }^{1} \triangle$, ZHIBEK K. ISSAYEVA², MARINA A. BRAGINA ${ }^{3}$, ZHANAR A. USINA ${ }^{4}$ \\ ${ }^{1}$ Institute of Psychology and Education, Kazan (Volga Region) Federal University, Kazan, Russian Federation \\ ${ }^{2}$ Center for Continuing Pedagogical Education, National Academy of Education named after Y. Altynsarin, Nur-Sultan, \\ Kazakhstan \\ ${ }^{3}$ Faculty of Russian Language and General Education Disciplines, Peoples' Friendship University of Russia, Moscow, \\ Russian Federation \\ ${ }^{4}$ Higher School of Art and Sports, Pavlodar State Pedagogical University, Pavlodar, Kazakhstan
}

\begin{abstract}
Thanks to the rapidly evolving technology, today's students are improving along with the digital world. The aim of this research was to study the level of students' knowledge of digital technology (computer, tablet computer, laptop, smartphones, interactive whiteboard and other digital devices). The authors used the following approaches observation, comparative investigations and synthesis of modern techniques to the formation of digital competencies of students, analysis of science, sociological, pedagogical and methodological literature; the study and implementation of various approaches, programs, mobile devices for the development of digital competence of students, the modelling of various approaches and pedagogical situations, the comprehension of their own experience. The study involved 37 students, future teachers of biology and English language of Kazan (Volga region) Federal University. The pedagogical essence and content of the concept "digital competence of the students" has been revealed, which consists in the fact that its development encourages students to constantly improve themselves, to personal and professional development. Defined pedagogical conditions aimed at improving the quality of knowledge of students using digital technologies in the educational space of Kazan (Volga region) Federal University. Developed a model for improving the quality of knowledge of students using various digital technologies in the educational process of the university. Criteria for the dynamics of the quality of knowledge of students using various digital technologies, tools and devices when studying at the university are determined. The results of the study can be used to formulate initiatives to develop the skills of the digital economy in the population.
\end{abstract}

Keywords: Digital literacy; Digital competence; Digital skills; Sports teacher; English teacher; Technology.

Cite this article as:

Salimzyanova, E.Sh., Issayeva, Z.K., Bragina, M.A., \& Usina, Z.A. (2021). Development of digital literacy and competence of future sports teachers in the physical and educational environment. Journal of Human Sport and Exercise, 16(3proc), S1181-S1187. https://doi.org/10.14198/ihse.2021.16.Proc3.34

Corresponding author. Institute of Psychology and Education, Kazan (Volga Region) Federal University, Kazan, Russian Federation.

E-mail: elmira.salimzyanova@inbox.ru

Abstract submitted to: Winter Conferences of Sports Science. Costa Blanca Sports Science Events, 22-23 March 2021. Alicante, Spain.

JOURNAL OF HUMAN SPORT \& EXERCISE ISSN 1988-5202.

(c) Faculty of Education. University of Alicante.

doi:10.14198/jhse.2021.16.Proc3.34 


\section{INTRODUCTION}

Digital in sport is one of the main technologies which has been considered in the previous studies (Means et al., 2013; Soltovets, Chigisheva \& Dmitrova, 2020; Caridade, 2019; Belonovskaya et al., 2020; Sintema, 2020; Elega, 2018: Hava \& Gelibolu, 2018; Chuechote et al., 2020; Bal, 2019; Mulenga \& Marbán, 2020; Çöteli, 2019; Molina-Toro, Rendón-Mesa \& Villa-Ochoa, 2019; Malamud \& Pop-Eleches, 2011; Nkata \& Dida, 2020). Kazan (Volga region) Federal University's students, future specialists of biology and English language, have similar digital literacy skills, like most Russian students at leading universities.

To prepare a competitive teacher, it is necessary to continue the formation of digital competencies at the university. A university teacher should contribute to the development of digital competencies of students. But more often it happens that the digital competencies of a professor lag behind the competencies of students. To solve this problem, it is advisable to talk about designing the educational space of the university, creating a special professionally-oriented environment for the formation of digital competence of both the teacher and the student. This environment should be created in accordance with the following principles: the definition of the learner as an active subject of knowledge; his orientation to self-education, self-development; reliance on the subjective experience of the student, taking into account his individual characteristics, training in the context of future professional activity (Horvath, 2016).

\section{Review of literature}

The creation of a digital economy in the framework of modern realities today requires an appropriate orientation of the education system, training a specialist who uses modern digital technologies in his activities. For a teacher to participate fully in the educational process, it is necessary to have digital literacy, which is considered as a key functional literacy, which allows expressing information needs, creating new information products using digital devices, digital resources, digital technologies and a willingness to participate in information and educational interaction (Ilomaki et al., 2011; Ruliene, 2016; Vinogradova et al., 2019; Kvon et al., 2019).

However, sometimes in educational institutions, the teachers themselves, ignoring the possibilities of modern digital technologies in learning, impede the effectiveness of educational activities. In the concept of "digital competency" we put the students confidently using a computer, mobile phone, tablet computer, interactive whiteboard, etc. This competency is based on logical thinking, a high level of mastery of information management and highly developed mastery of digital technology (Horvath, 2016; Shinkevich et al., 2020).

In this competency, some researchers propose to include the following knowledge: understanding of the general structure and interaction of computer equipment, digital devices, software, digital resources; understanding the potential of digital technology for innovation; basic understanding of the reliability and reliability of the information received, the ability to use programs for designing a training session (Quarles et al., 2018).

Some researchers argue that in the preparation of teachers it is necessary to form digital competencies, since the success of students' results depends on them in the future. Others consider that it is essential to design the educational space of the university and the classroom should meet the modern requirements and demands of the digital society (Demarle-Meusel, Sabitzer \& Sylle, 2017). 


\section{MATERIALS AND METHODS}

In our study we used the following research methods: observation, comparative analysis and synthesis of modern approaches to the formation of digital competencies of students, analysis of science, sociological, pedagogical and methodological literature; the study and implementation of various approaches, programs, mobile devices for the development of digital competence of students, the modelling of various approaches and pedagogical situations, the comprehension of their own experience.

At the first stage of the formation and development of digital competence, the student must realize the importance and necessity of using computer and digital technologies in modern society. Besides, at the first stage, we conducted a sociological survey in the form of a survey, as a result of which were interviewed by 37 students, future teachers of biology and English. Also, using diagnostic testing, we identified the degree of knowledge of digital technologies.

At the second stage, students complete tasks aimed at acquiring practical skills in working with different programs to solve educational and practice-oriented tasks in their future professional activities. This stage of the study is devoted to monitoring the activities of future teachers through intermediate tests.

The third stage of the study shows the dynamics and level of knowledge of digital technologies of each individual student. We came to certain conclusions, for example, that the experience of using digital technologies changes the position of the teacher (deepens professionalism, expands the scope of the knowable). The teacher ceases to be a "source of knowledge" but becomes the creator of the creative process of processing the use of information and a more active participant in the formation of the personality of the future specialist in the digitalization era.

\section{RESULTS AND DISCUSSION}

The study involved the following stages of experimental work: at the first stage of the formation and development of digital literacy and digital competence, a future graduates of the Kazan (Volga) Federal University, studying in the field of training 44.03.05 Pedagogical education (with two provisioning profiles), 2 profiles: "Biology" and "English language") should realize the importance and necessity of using computer and digital technologies in the realities of modern society. At the first stage of the formation and development of digital literacy and digital competence, the student must realize the importance and necessity of using computer and digital technologies. In the first classes, the main task of the teacher is the formation and development of a future specialist's motivation to use digital technologies in the university and in later life, in their professional activities. At this stage, the teacher using questionnaires and diagnostic testing reveals the degree of ownership of specific digital technologies, the correct application of the conceptual-categorical apparatus (knowledge of terminology), etc. Entrance testing allows the teacher to make adjustments to the organization of the educational process, taking into account the capabilities and potential of students, their preferences and interests, to plan individual independent work of students aimed at filling the gaps in the framework of the studied discipline.

The next stage is substantive and active. At this stage, students perform various tasks aimed at acquiring practical skills in working with different programs to solve educational and practice-oriented tasks in their future professional activities. The main goal of this stage is to create automatism when working with digital technology (computer, tablet computer, smartphones, interactive whiteboard): create presentations, know 
the basics of programming, search for information on the Internet, work with graphic data, the ability to draw up text documents, perform calculations using formulas and functions in spreadsheets, etc.

Using resources on the Internet allows you to teach students to work with huge and often conflicting arrays of information, to be able to quickly carry out information retrieval, analyse the information received and use it in educational and professional activities. Of great importance is the use in the performance of many tasks of a variety of practical tasks oriented to professional activities. Students must learn how to effectively use computer science knowledge to solve educational and professional problems. Trainees at this stage are supervised by the teacher with the help of intermediate tests, if necessary, an adjustment is possible according to the number and level of difficulty of the tasks during practical work (Demarle-Meusel, Sabitzer, \& Sylle 2017).

Structuring into separate elements of the content of training (sections) allows you to track the level of formation and development of digital literacy and digital competence. Active and interactive teaching methods used in the classroom bring students a productive and creative character.

The productive and reflective stage of the development of digital literacy and digital competence of students shows the dynamics and level of knowledge of digital technologies. Evaluation of the development of digital competency is carried out through the participation of students in Internet testing. Evaluation of the formation of digital competencies are four levels of knowledge acquisition (Bespalko, 2006). Testing results allow you to focus on the achievements of each individual first-year student, evaluate the level of formation of digital competence within the framework of the discipline under study.

The experiment involved 37 students. The study showed that 37 students (100\%) have good working skills with a stationary computer, since they were acquired at school. But worse were the results of owning a tablet computer: only $60 \%$ of students familiar with the programs on a tablet computer. $85 \%$ of students are wellversed in smartphone applications. $80 \%$ of students know how to use an interactive whiteboard. Not every student has a new smartphone, so it is difficult to work with applications. In preparation for the seminar use video materials from YouTube - 8\% of students; preferred presentation performance - 40\%; oral communications $-55 \%$ of students.

After the study, we decided, firstly, to organize a special laboratory to provide advisory assistance to students and teachers, to conduct additional classes for one group of students in teaching digital media programs. After their training, we came to the conclusion that students with the desire to learn, easily absorb information on working with digital media. Thus, we came to the conclusion that in the curriculum for future biology and English teachers it is necessary to include the study of programs in digital media, the knowledge of which will be useful to them in further practical activities in educational organizations.

Currently, the teacher needs to plan, organize and direct the learning process in accordance with changing ideas about the student's readiness to perform professional functions and social roles, provide conditions for preparing for life in changing socio-economic conditions, demonstrating the diversity of the use of information environments and basic knowledge gained The study of new information environments makes it possible to identify to the future specialist the advantages and disadvantages of these programs and thereby determine the degree of their effective use in practice. 


\section{CONCLUSION}

After the study, we decided to organize a special laboratory to provide advisory assistance to students and teachers, to conduct additional classes for one group of students in teaching programs for working with digital media. After their training, we came to the conclusion that students enthusiastically learn, easily absorb information on working with digital media. We also came to the conclusion that in the curriculum for future biology and English teachers it is necessary to include the study of programs on digital media, the knowledge of which will be useful to them in further practical activities in educational organizations. We believe that when organizing educational and research activities it is advisable to use tablet computers, various mobile applications, an interactive whiteboard in conjunction with circuit modelling systems in the educational research environment, which will increase the level of information and digital competence of students, master the natural-scientific methods of cognition and basic research procedures and processing the results of information. Thus, students will be able to critically interpret the results of the analysis of the computer model of the process under study and increase the level of understanding of the theoretical material and its practical orientation, learn how to create virtual experimental setups and computer models of the studied phenomenon, etc. The experience of using information technology changes the position of the teacher: he ceases to be a "source of knowledge" and becomes the creator of the creative process of processing, use of information and a more active participant in shaping the personality of the future teacher. The study of new information environments makes it possible to identify the future specialist the strengths and weaknesses of these programs and thereby determine the degree of their effective use in practice. As a result of the study, we came to the conclusion that in the university it is necessary to have a laboratory where not only computers, but also tablet computers, modern smartphones must be in order to teach humanitarian students digital technologies in the classroom, since their level of knowledge of various digital programs media insufficient for creative use in practical teaching activities. The results of the study can be used to formulate initiatives to develop the skills of the digital economy in the population. The result also makes it possible to argue that as the role of human capital for the digital economy grows, it becomes essential to carry out initiatives to form new competencies, affecting the teaching staff of universities and schools.

\section{ACKNOWLEDGMENTS}

The work is performed according to the Russian Government Program of Competitive Growth of Kazan Federal University.

\section{REFERENCES}

Alviram, A. \& Eshet-Alkalai, Y. (2006). Towards a theory of digital literacy: Three scenarios for the next steps. European Journal of Open Distance E-Learning. URL: http:// www.eurodl.org/materials/contrib/2006/Aharon Aviram.htm

Bal, M. (2019). Use of Digital Games in Writing Education: An Action Research on Gamification. Contemporary Educational Technology, 10(3), 246-271. https://doi.org/10.30935/cet.590005

Belonovskaya, I.D., Matvievskaya, E.G., Saitbaeva, E.R., Ksenofontova, A.N., Usmanov, S.M., Zatsepina, M.B. \& Bakshaeva, E.V. (2020). Digital Communication in Educational Process: Development Trends and New Opportunities. Online Journal of Communication and Media Technologies, 10(2), e202008. https://doi.org/10.29333/ojcmt/7928

Bespalko, V.P. (2006). Parameters and criteria of the diagnostic target. School technologies, 1, 118-128. 
Caridade, C.M.R. (2019). Applications (Ideas) in Linear Algebra with Digital Image Processing. Can we Do, Teach, Motivate and Evaluate?. Journal of Information Systems Engineering and Management, 4(4), em0103. https://doi.org/10.29333/iisem/6347

Chuechote, S., Nokkaew, A., Phongsasithorn, A. \& Laosinchai, P. (2020). A Neo-Piagetian Analysis of Algorithmic Thinking Development through the "Sorted" Digital Game. Contemporary Educational Technology, 12(1), ep261. https://doi.org/10.30935/cet.685959

Çöteli, S. (2019). The Impact of New Media on The Forms of Culture: Digital Identity and Digital Culture. Online Journal of Communication and Media Technologies, 9(2), e201911. https://doi.org/10.29333/ojcmt/5765

Demarle-Meusel, H., Sabitzer, B. \& Sylle, J. (2017). The teaching-learning-lab: Digital literacy \& computational thinking for everyone. CSEDU 2017 - Proceedings of the 9th International Conference on Computer Supported Education, 2, 166-170. https://doi.org/10.5220/0006367001660170

Elega, A.A. (2018). Digital Conversations on the Blogosphere. Online Journal of Communication and Media Technologies, 8(2), 39-54. https://doi.org/10.12973/ojcmt/2353

Fross, K., Winnicka-Jasłowska, D. \& Sempruch, A. (2018) «Student zone» as a new dimension of learning space. Case study in Polish conditions. Advances in Intelligent Systems and Computing, 600, 77-83. AHFE 2017 International Conference on Human Factors, Sustainable Urban Planning and Infrastructure, 2017). Los Angeles: United States. https://doi.org/10.1007/978-3-319-60450-3 8

Hava, K. \& Gelibolu, M.F. (2018). The Impact of Digital Citizenship Instruction through Flipped Classroom Model on Various Variables. Contemporary Educational Technology, 9(4), 390-404. https://doi.org/10.30935/cet.471013

Horvath, I. (2016). Digital life gap between students and lecturers. 7th IEEE International Conference on Cognitive Infocommunications, 10, 353-358. https://doi.org/10.1109/Cog InfoCom.2016.7804575

Ilomaki, L., Lakkala, M., Kantosalo, A. \& Paavola, S. (2011). Digital competence - an emergent boundary concept for policy and educational research. Education and Information Technologies, 21(3), 655679. https://doi.org/10.1007/s10639-014-9346-4

Janks, H. (2010). Language, power and pedagogy. In N. Hornberger and S. McKay (Eds). Sociolinguistics and Language Education. Clevedon: Multilingual Matters. https://doi.org/10.21832/9781847692849-004

Kay, R.H. (2006). Evaluating strategies used to incorporate technology into pre-service education: A review of the literature. Journal of Research on Technology in Education and Information Technologies, 38(4), 383-408. https://doi.org/10.1080/15391523.2006.10782466

Krumsvik, R.J. (2014). Teacher educators' digital competence. Scandinavian Journal of Educational Research, 58(3), 269-280. https://doi.org/10.1080/00313831.2012.726273

Kuzminska, O., Mazorchuk, M., Morze, N., Pavlenko, V. \& Prokhorov, A. (2018). Digital competency of the students and teachers in Ukraine: Measurement, analysis, development prospects. Proceedings of the 14th International Conference on ICT in Education, Research and Industrial Applications. Integration, Harmonization and Knowledge Transfer. ICTERI'2018, Kyiv, Ukraine (May, 14-17, 2018), pp. 366-379.

Kvon, G.M., Prokopyev, A.I., Shestak, V.A., Larionova, A.A., \& Shikh, E.V. (2019). Features of cost advantages from implementation of energy-saving projects. International Journal of Energy Economics and Policy, 9(3), 53-58. https://doi.org/10.32479/ijeep.7645

Malamud, O. \& Pop-Eleches, C. (2011). Home computer use and the development of human capital. The Quarterly Journal of Economics, 126(2), 987-1027. https://doi.org/10.1093/qje/qir008

Means, B., Toyama, Y., Murphy, R.F. \& Baki, M. (2013). The Effectiveness of Online and Blended Learning: A Meta-Analysis of the Empirical Literature. Teachers College Record, 115, 1-47. 
Mishra, P. \& Koehler, M.J. (2006). Technological Pedagogical Content Knowledge: A Framework for Teacher Knowledge. Teachers College Record, 108(6), 1017-1054. https://doi.org/10.1111/j.14679620.2006.00684.x

Molina-Toro, J.F., Rendón-Mesa, P.A. \& Villa-Ochoa, J.A. (2019). Research Trends in Digital Technologies and Modeling in Mathematics Education. Eurasia Journal of Mathematics, Science and Technology Education, 15(8), em1736. https://doi.org/10.29333/ejmste/108438

Mulenga, E.M. \& Marbán, J.M. (2020). Is COVID-19 the Gateway for Digital Learning in Mathematics Education?. Contemporary Educational Technology, 12(2), ep269. https://doi.org/10.30935/cedtech/7949

Nawaz, A. \& Kundi, G.M. (2010). Digital literacy: An analysis of the contemporary paradigms. International Journal of Science and Technology Education Research, 1(2), 19-29.

Nkata, A.S. \& Dida, M.A. (2020). A Framework for Implementing an Education Management Information System in Tanzanian Secondary Schools to Improve Delivery of Quality Education and Students' Academic Achievement. Journal of Information Systems Engineering and Management, 5(2), em0113. https://doi.org/10.29333/iisem/7858

Quarles, A.M., Conway, C.S., Harris, S., Osler, J. \& Rech, L. (2018). Integrating digital/mobile learning strategies with students in the classroom at the historical black college/university (HBCU). Handbook of Research on Digital Content, Mobile Learning, and Technology Integration Models in Teacher Education, 13, 390-408. https://doi.org/10.4018/978-1-5225-2953-8.ch020

Ruliene, L.N. (2016). Digital literacy and humanitarian culture of a teacher in innovative educational practice. Open and distance education, 4(64), 53-58. https://doi.org/10.17223/16095944/64/8

Shinkevich, M.V., Mashkin, N.A., Ishmuradova, I.I., Kolosova, V.V., \& Popova, O.V. (2020). Management of sustainable consumption of energy resources in the conditions of digital transformation of the industrial complex. International Journal of Energy Economics and Policy, 10(5), 454-460. https://doi.org/10.32479/ijeep.10202

Sintema, E.J. (2020). E-Learning and Smart Revision Portal for Zambian Primary and Secondary School Learners: A Digitalized Virtual Classroom in the COVID-19 Era and Beyond. Aquademia, 4(2), ep20017. https://doi.org/10.29333/aquademia/8253

Soltovets, E., Chigisheva, O. \& Dmitrova, A. (2020). The Role of Mentoring in Digital Literacy Development of Doctoral Students at British Universities. Eurasia Journal of Mathematics, Science and Technology Education, 16(4), em1839. https://doi.org/10.29333/ejmste/117782

Vinogradova, G.A., Akhmadieva, R.Sh., Konovalova, V.M., Spirina, E.V., Kalugina, O.A., Erdyneeva, K.G., Popova, N.N., \& Mashkin, N.A. (2018). Releasers as Factor of Student Ecological Focus Formation. Ekoloji, 27(106), 1409-1415.

\section{@) $\oplus \Theta \Theta$}

This work is licensed under a Attribution-NonCommercial-NoDerivatives 4.0 International (CC BY-NC-ND 4.0). 